\title{
Der Autor:
}

Dr. Carsten Wieland ist Redakteur und arbeitet derzeit beim Goethe-Institut. Als Korrespondent der Deutschen Presse-Agentur (dpa) berichtete er unter anderem aus dem Nahen Osten, den USA und Kolumbien. Syrien kennt der Journalist seit vielen Jahren. Zuletzt lebte er dort von 2003 bis 2004. Wieland hat Geschichte, Politik, Philosophie und Internationale Beziehungen an der Humboldt-Universität Berlin, an der Duke University in North Carolina (USA) und an der Jawaharlal Nehru Universität in Neu-Delhi (Indien) studiert. Er schrieb mehrere wissenschaftliche Artikel zum Thema Nationalismus und promovierte über einen Vergleich zur muslimischen Nationsbildung und ethnischen Konflikten in Bosnien und Indien/Pakistan. Während des BosnienKriegs berichtete Wieland als freier Journalist aus Sarajevo.

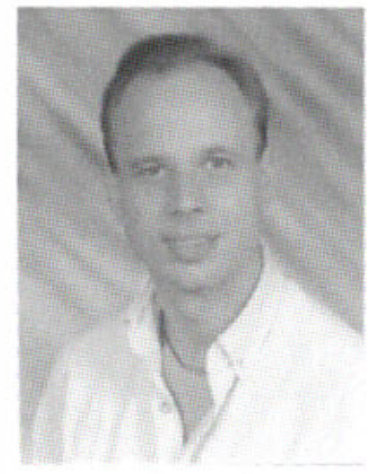

